\title{
COMPARISON OF THE TALK TEST AND PERCENT HEART RATE RESERVE FOR EXERCISE PRESCRIPTION
}

\author{
John P. Porcari, Katelyn Falck-Wiese, Samantha Suckow-Stenger, \\ Jillian Turek, Anna Wargowsky, Maria L. Cress, Scott T. Doberstein, \\ Chelsea J. Hahn, Abigail L. Ryskey, and Carl Foster \\ Department of Exercise and Sport Science, University of Wisconsin-La Crosse, USA
}

Original scientific paper
https://doi.org/10.26582/k.50.1.8
UDC: $796.015: 612.1$

\begin{abstract}
:
Exercise intensity is traditionally prescribed using $\% \mathrm{HR} \max , \% \mathrm{HRR}, \% \mathrm{VO}_{2} \max$, or $\% \mathrm{VO}_{2} \mathrm{R}$. Recently, the Talk Test (TT) has been proposed as an alternative method to guide exercise intensity. However, it is unknown if prescribing exercise intensity solely using the TT can provoke training responses that are comparable to traditional guidelines. This study compared the responses to training using either the TT or \%HRR. Forty-four subjects (17 males and 27 females: age $=20.4 \pm 3.02$ years; body height $=170.5 \pm 9.79 \mathrm{~cm}$; body weight $=71.9 \pm 13.63 \mathrm{~kg}$ ) completed an incremental maximal cycle ergometer test, were stratified by $\mathrm{VO}_{2} \mathrm{max}$ and gender, and randomly assigned to training groups guided by either $\% \mathrm{HRR}(\mathrm{n}=20)$ or the TT $(\mathrm{n}=24)$. Both groups completed 40 -minute training sessions three days per week for 10 weeks. In the HRR group, exercise intensity was targeted (per ACSM guidelines) at 40-59\% HRR for weeks 1-4, 50-59\% HRR for weeks 5-8, and 60-79\% HRR for weeks 9-10. In the TT group, exercise intensity was targeted at the highest power output (PO) that still allowed for comfortable speech. Changes in $\mathrm{VO}_{2} \mathrm{max}$, peak power output (PPO), $\mathrm{VO}_{2}$ at ventilatory threshold (VT), and $\mathrm{PO}$ at VT were compared between the groups using two-way ANOVA with repeated measures. There were significant $(\mathrm{p}<.05)$ pre vs. post increases in $\mathrm{VO}_{2} \max (\mathrm{TT}=10.6 \%$; HRR $=11.5 \%)$, PPO (TT=19\%; HR=14\%), $\mathrm{VO}_{2}$ at VT $(\mathrm{T}=32.7 \%$; $\mathrm{HRR}=56.9 \%)$, and $\mathrm{PO}$ at $\mathrm{VT}(\mathrm{TT}=43.1 \%$; $\mathrm{HRR}=38.6 \%)$ in both groups, with no significant $(\mathrm{p}>0.05)$ interaction effect. Guiding exercise prescription using the TT is a simple and effective method for prescribing exercise intensity and elicits improvements in exercise performance that are comparable to the traditional \%HRR guidelines.
\end{abstract}

Key words: training, ventilatory threshold, aerobic capacity, session RPE, enjoyability

\section{Introduction}

Classically, exercise training is prescribed on the basis of percent heart rate max (\%HRmax), percent heart rate reserve (\%HRR), percent maximal oxygen consumption $\left(\% \mathrm{VO}_{2} \mathrm{max}\right)$, or percent maximal oxygen consumption reserve $\left(\% \mathrm{VO}_{2} \mathrm{R}\right)$, based on the results of a maximal graded exercise test (Riebe, 2017). However, within the last 20 years, the use of graded exercise testing before either clinical or fitness exercise programs has declined, with less than $5 \%$ of participants having a maximal exercise test available to guide exercise prescription. Despite the considerable evidence base supporting $\% \mathrm{VO}_{2}$ max and $\% \mathrm{HRR}$ as reference training guidelines, there have been persistent suggestions that a given 'relative percent' of maximal values may not produce highly consistent inter-individual metabolic responses to exercise (Katch, Weltman, Sady, \& Freedson, 1978; Scharhag-Rosenberger, Meyer, Gassler, Faude, \& Kinderman, 2010). This has led to consensus recommendations that exercise prescription be based on 'threshold concepts' rather than the 'relative percent of maximal' concept (Mezzani, et al., 2012). However, even if exercise prescriptions were to be based on threshold concepts, a maximal exercise test with either respiratory gas exchange or blood lactate measurement would be required, which is not widely available to the exercise community outside of research settings.

Given the lack of availability of maximal exercise tests, and evidence that age-predicted maximal $\mathrm{HR}$ is an inadequate method of guiding individual exercise prescription (Robergs \& Landwehr, 2002), the emphasis during the last 20 years has been on subjective methods of guiding exercise prescription. The Rating of Perceived Exertion (RPE) (Borg, 1998; Eston, 2012) scale has been shown to be a useful surrogate of exercise intensity, either as a momentary rating (Pollock, Foster, Rod, \& Wible, 1982) or as a surrogate for the entire exercise bout 
(Foster, et al., 2001). Recent evidence has demonstrated that training at a theoretically optimal RPE of 13 (i.e., somewhat hard) leads to predictable changes in $\mathrm{VO}_{2} \max$ and ventilatory threshold (VT), which are of the same magnitude as observed in the traditionally guided exercise training programs (Parfitt, Evans, \& Eston, 2012).

An alternative to RPE, the Talk Test (TT), has received attention during the last 25 years as a method of guiding exercise training intensity. The Talk Test is based on traditional concepts that "the highest exercise intensity at which you can still speak is just about the right exercise training intensity." The earliest reference (Goode, 2008) to the TT concept is the suggestion to mountaineers, attributed to Professor John Grayson, in 1937, to "climb no faster than you can talk." Goode, Mertens, Shaiman, and Mertens (1998) presented the first systematically collected data demonstrating that the exercise intensity that caused exercisers to 'hear their breathing' produced a training HR within conventional training guidelines, and approximated the VT. Brawner, Keteyian, and Czaplicki (1995) also demonstrated that when walking or arm-leg cycling intensity was regulated by the ability to respond verbally to a standardized questionnaire, HR was within conventional guidelines. More recent studies have demonstrated that the exercise intensity at which people first 'have difficulty speaking comfortably' (using a variety of speech producing stimuli) is a reliable surrogate of the VT in healthy individuals (Dehart-Beverley, Foster, Porcari, Fater, \& Mikat, 2000; Foster, et al., 2009a; Loose, et al., 2012; Norman, Hopkins, \& Crapo, 2008; Quinn, \& Coons, 2011), athletes (Jeans, Foster, Porcari, Gibson, \& Doberstein, 2011; Rodriguez-Marroyo, Villa, Garcia-Lopez, \& Foster, 2013; Woltmann, et al., 2015), patients with cardiovascular disease (Brawner, et al., 2006; Lyon, et al., 2014; Voelker, et al., 2001; Zanettini, et al., 2013) and patients with spinal cord injury (Cowan, Ginnity, Kressler, \& Nash, 2012). The exercise intensity at which subjects 'definitely cannot speak comfortably' has been shown to be associated with the respiratory compensation threshold (RCT) (Recalde, et al., 2002; Rodriguez-Marroyo, et al., 2013; Woltmann, et al., 2015). Recent studies have demonstrated that the requirement for suppressing breathing frequency to allow speech, leads to a reduction in $\mathrm{VCO}_{2}$, which would be critically important given the increase in $\mathrm{VCO}_{2}$ at VT. This leads to a striking increase in $\mathrm{PetCO}_{2}$, a surrogate of $\mathrm{PaCO}_{2}$, which likely strongly influences the sense of speech comfort during exercise (Creemers, Foster, Porcari, Cress, \& de Koning, 2017). The TT appears to be consistent across modes of exercise (Persinger, et al., 2004) and is reliable (Ballweg, et al., 2013; Nielsen, et al., 2014; Petersen, Maribo, Hjortdal, \& Laustsen, 2014). In patients with ST-segment depression during clinical exercise testing, speech becomes 'less than comfortable' prior to the first electrocardiographic evidence of exercise induced ischemia (Cannon, et al., 2004), which suggests the value of the TT at contributing to the safety of exercise in patients (Foster, et al., 2008b). Further, the TT appears to be responsive to interventions such as stochastic changes in exercise intensity, venesection, and exercise training (Foster, et al., 2008a), and is robust relative to translating exercise testing responses into exercise training recommendations across populations (Foster, et al., 2009; Jeans, et al., 2011; Lyon, et al., 2014; Woltmann, et al., 2015).

Thus, it appears that the TT has considerable potential as a subjective tool for guiding exercise training intensity, and has the advantage of not requiring a preliminary exercise test. What is not known, however, is how well the TT works in provoking training responses compared to an established technique such as \%HRR. Therefore, the purpose of this study was to make a systematic comparison of the response to training in healthy, sedentary young-adults when the TT is compared to $\% \mathrm{HRR}$ as a strategy for guiding exercise training intensity.

\section{Methods}

\section{Subjects}

The subjects for the study were healthy, university-aged individuals, who were sedentary. The subjects were screened with the PAR-Q to identify individuals who should not participate in the study and with an exercise questionnaire to exclude active individuals. Any subject who exercised regularly ( $>3$ days weekly) or any subject who performed vigorous exercise (typically intramural game participation in this population) >1-day weekly was excluded. Additionally, after pre-testing, any male with a $\mathrm{VO}_{2} \max >50 \mathrm{~mL} \cdot \mathrm{kg}^{-1} \mathrm{~min}^{-1}$ and any female with a $\mathrm{VO}_{2} \max >43 \mathrm{~mL} \cdot \mathrm{kg}^{-1} \mathrm{~min}^{-1}$ was excluded from the study. All subjects provided written informed consent prior to the study. The protocol, which followed the principles of the Declaration of Helsinki, had been approved by the University Human Subjects Committee. Descriptive characteristics of the subjects who completed the study are presented in Table 1.

\section{Testing procedures}

Pre- and post-training incremental maximal exercise was performed on an electrically-braked cycle ergometer (Lode Excalibur, Groningen, NL). The initial power output (PO) was 25 watts, and was increased by 25 watts every two minutes until the subject could not sustain a pedaling rate in the range of 60-80 rpm. Respiratory gas exchange was measured using open-circuit spirometry with a mixing chamber-based metabolic system (AEI Moxus, 
Table 1. Descriptive characteristics of the subjects at the beginning of the study. Values presented represent mean \pm standard deviation

\begin{tabular}{lcc}
\hline & $\begin{array}{c}\text { Talk Test } \\
(\mathrm{n}=20)\end{array}$ & $\begin{array}{c}\text { Heart Rate } \\
\text { Reserve }(\mathrm{n}=24)\end{array}$ \\
\hline Age (years) & & \\
Males (17) & $21.2 \pm 2.82$ & $21.0 \pm 5.90$ \\
Females (27) & $20.5 \pm 1.97$ & $19.5 \pm 1.26$ \\
Height (cm) & & \\
Males & $179.5 \pm 7.27$ & $176.9 \pm 3.97$ \\
Females & $165.0 \pm 9.84$ & $166.0 \pm 7.74$ \\
Weight (kg) & & \\
Males & $83.9 \pm 10.63$ & $77.0 \pm 14.55$ \\
Females & $67.6 \pm 10.72$ & $65.5 \pm 11.80$ \\
\hline
\end{tabular}

Pittsburgh, PA), with calibration of the gas analyzers using a reference gas $\left(14 \% \mathrm{O}_{2}, 7 \% \mathrm{CO}_{2}\right)$ and room air. The pneumotach was calibrated before each test using a 3L syringe. Gas exchange was computed for each 30 seconds of the test, and the highest 30 second value was accepted as a $\mathrm{VO}_{2}$ max, with the requirement that the test was subjectively maximal and that the RER $>1.1$. Ventilatory threshold (VT) was identified on the basis of both the v-slope and ventilatory equivalent methods by two experienced observers. When the two observers did not agree, the third experienced observer was consulted.

In a previous study (Foster, et al., 2015), we had observed decreases in the enjoyment of exercise across the duration of a controlled training study. To follow up on those results, one day each week during the training period exercise enjoyment was assessed five minutes before, at the midpoint, and five minutes after the training session using the Exercise Enjoyment Scale (Stanley \& Cumming, 2010).

After pre-testing, the subjects were stratified by their fitness $\left(\mathrm{VO}_{2}\right.$ max in $\left.\mathrm{mL} \cdot \mathrm{kg}^{-1} \cdot \mathrm{min}^{-1}\right)$ (e.g., the most fit male in the \%HRR group, $2^{\text {nd }}$ most fit male in the TT group, designed to allow matching as close as possible between the groups) and gender, and then randomly assigned to training groups where the control of training was provided using either the $\%$ HRR method or the TT. The training intervention was 10 weeks in duration and consisted of $3 \times$ 40-minute sessions per week. If a subject missed a training session in one week, they performed four sessions during the subsequent week, such that all subjects performed 30 training sessions during the 10 -week intervention period. All training was conducted on mechanically-braked cycle ergometers (Monarch, Stockholm, SE). Pedaling rate was set at $60 \mathrm{rpm}$, and was reinforced both with the ergometer display and with music at a dominant beat frequency of $120 \mathrm{bpm}$. Adjustments in training PO were accomplished by increasing the resistance on the flywheel. With this ergometer, at a pedaling rate of $60 \mathrm{rpm}$, an increase in flywheel resistance of $0.5 \mathrm{~kg}$ equaled $\sim 30 \mathrm{~W}$. All sessions began and ended with 5-minute warm-up and cool-down periods at $\sim 30 \mathrm{~W}$. During the remaining 30 minutes of the training session, intensity was regulated either by $\%$ HRR or the TT.

In the TT group, the initial PO was set one stage below the PO at VT during pre-testing. After five minutes, the subject recited, aloud, a 101-word standard paragraph (the Rainbow Passage) (DehartBeverley, et al., 2000; Schroeder, Foster, Porcari, \& Mikat, 2017) and was asked "Can you speak comfortably?". If the answer was "Yes" (positive), the PO was increased by $\sim 30 \mathrm{~W}$. If the answer was "Yes, but" (equivocal) or "No" (negative), the PO was decreased by $\sim 30 \mathrm{~W}$. This process was repeated every five minutes throughout each training session, with the intent of keeping the subject at the highest intensity that just allowed comfortable speech. Although not used to regulate training intensity, RPE and HR were measured at each 5-minute interval. Five minutes following the conclusion of the training session, session RPE (sRPE) was measured using a modification of the Category Ratio RPE scale (Christen, Foster, Porcari, \& Mikat, 2016; Foster, et al., 2001).

In the HRR group, the initial PO was set (Riebe, 2017) to achieve a HR of $40-59 \%$ HRR during the first four weeks. Heart rate was measured every five minutes using radiotelemetry and the workload was adjusted, in steps of $\sim 30 \mathrm{~W}$, to keep the \%HRR in the desired training zone. After four weeks, target HR was increased to $50-69 \% \mathrm{HRR}$, and after eight weeks to $60-79 \%$ HRR. Although not used to adjust training, PO and RPE were measured every five minutes and sRPE was assessed five minutes post exercise, as with the TT group.

\section{Statistical analysis}

Statistical analyses were conducted using two-way repeated measures ANOVA for a groupsby-trials model. Training data were analyzed using a groups-by-time (weeks) model. When statistically significant differences were indicated by ANOVA, pairwise comparisons were made using Tukey's post-hoc procedures. Alpha was set at $\mathrm{p}<.05$ to achieve statistical significance for all analyses.

\section{Results}

Originally, 54 subjects were recruited and participated in the pre-training evaluations. However, six individuals (three males and three females) were not included in the study for having a high pre-test $\mathrm{VO}_{2}$ max, one individual dropped out for an injury unrelated to training, one individual dropped due to illness, and two subjects dropped out from the study due to lack of time for training. Thus, 44 subjects completed the study. 




Figure 1. Acute training responses in the Talk Test (TT) (closed symbols) and Heart Rate Reserve (HRR) (open symbols) groups across the 10 weeks of training. Data represent mean and standard deviation. Significant differences between the groups are represented by an asterisk (*). There were no significant interaction terms within the data analysis.

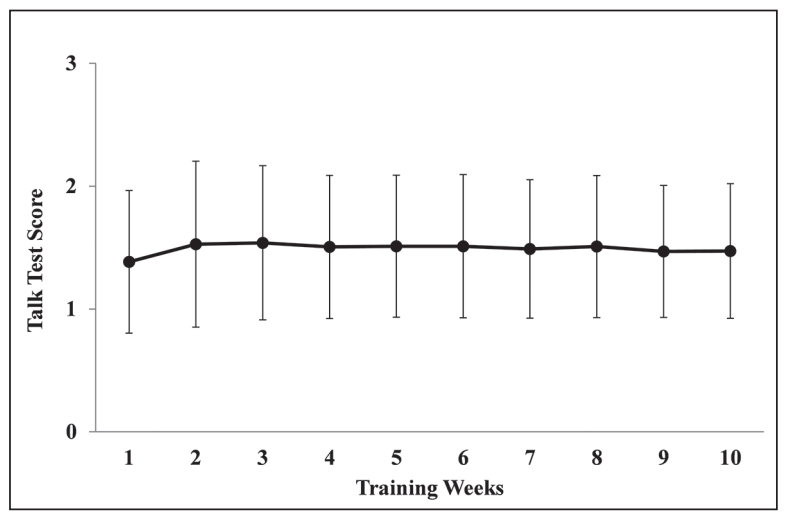

Figure 2. Average Talk Test score during training for subjects in the Talk Test group across the 10 weeks of training $(1=$ positive response; 2 = equivocal response; 3 = negative response). Data represent mean and standard deviation.
Acute responses during training are presented in Figures 1 and 2. Training intensity, whether expressed as PO (watts $\mathrm{kg}^{-1}$ ), \%HRR, or RPE, was significantly higher in the TT group during the first eight weeks of training, secondary to following established protocols for the progression of training using the \%HRR method (Riebe, 2017) (Figure 1). As the progression scheme recommended by ACSM increased with progress through the training program, the differences between the \%HRR and TT groups gradually declined. The training intensity observed in the TT group was remarkably constant throughout the training period ( $70-75 \%$ HRR, RPE 13-14), and the relative speech difficulty remained in the target range, i.e., just below the equivocal (+/-) stage of the TT (Figure 2). Overall, the training intensity in both groups fell within the recommended training window for all measures. As expected in a training study, there was a progression of $\mathrm{PO}$ during training in both groups, reflecting that a higher $\mathrm{PO}$ was required to satisfy the monitoring criteria for training intensity.

Peak power output (watts $\mathrm{kg}^{-1}$ ) (TT vs. \%HRR groups, +19 vs. $+13 \%)$ and $\mathrm{VO}_{2} \max \left(\mathrm{mL} \cdot \mathrm{kg}^{-1} \cdot \mathrm{min}^{-1}\right)$ $(+10.8$ vs. $+14.4 \%)$ increased significantly and similarly in both training groups (Figure 3), top and middle left. Maximal HR did not change in either group ( +1.1 vs. $+1.5 \%$ ) (Figure 3, bottom left). Power output at VT (watts.kg-1) $(+45$ vs. $+41 \%)$ and $\mathrm{VO}_{2}$ at VT $\left(\mathrm{mL} \cdot \mathrm{kg}^{-1} \cdot \mathrm{min}^{-1}\right)(+19$ vs. $+13 \%)$ increased significantly and similarly in both groups (Figure 3, top and middle right). Heart rate at VT also increased significantly and similarly in both groups (+9.1 vs. $+9.9 \%$ ) (Figure 3, bottom right).

There was a statistically significant decrease in exercise enjoyability over the 10 -week training intervention. There were no differences in the responses between the training groups and no group by time interaction (Figure 4).

\section{Discussion and conclusions}

The major finding of this study was that exercise capacity, whether measured as $\mathrm{PO}$ or $\mathrm{VO}_{2}$, at both the maximal exercise and at the VT, improved to the same extent regardless of whether the intensity of training was guided by the conventional exercise prescription criteria (\%HRR) (Riebe, 2017) or by the TT. The other major finding of this study was a decrease in enjoyment of the exercise training bouts across the course of the study, regardless of how the training intensity was controlled.

The magnitude of improvement in exercise capacity $\left(\sim 11 \%\right.$ for $\mathrm{VO}_{2}$ max $)$ in both groups was of similar magnitude as normally observed in training studies of this duration (Gormley, et al, 2008; Pollock, 1973), particularly considering that 


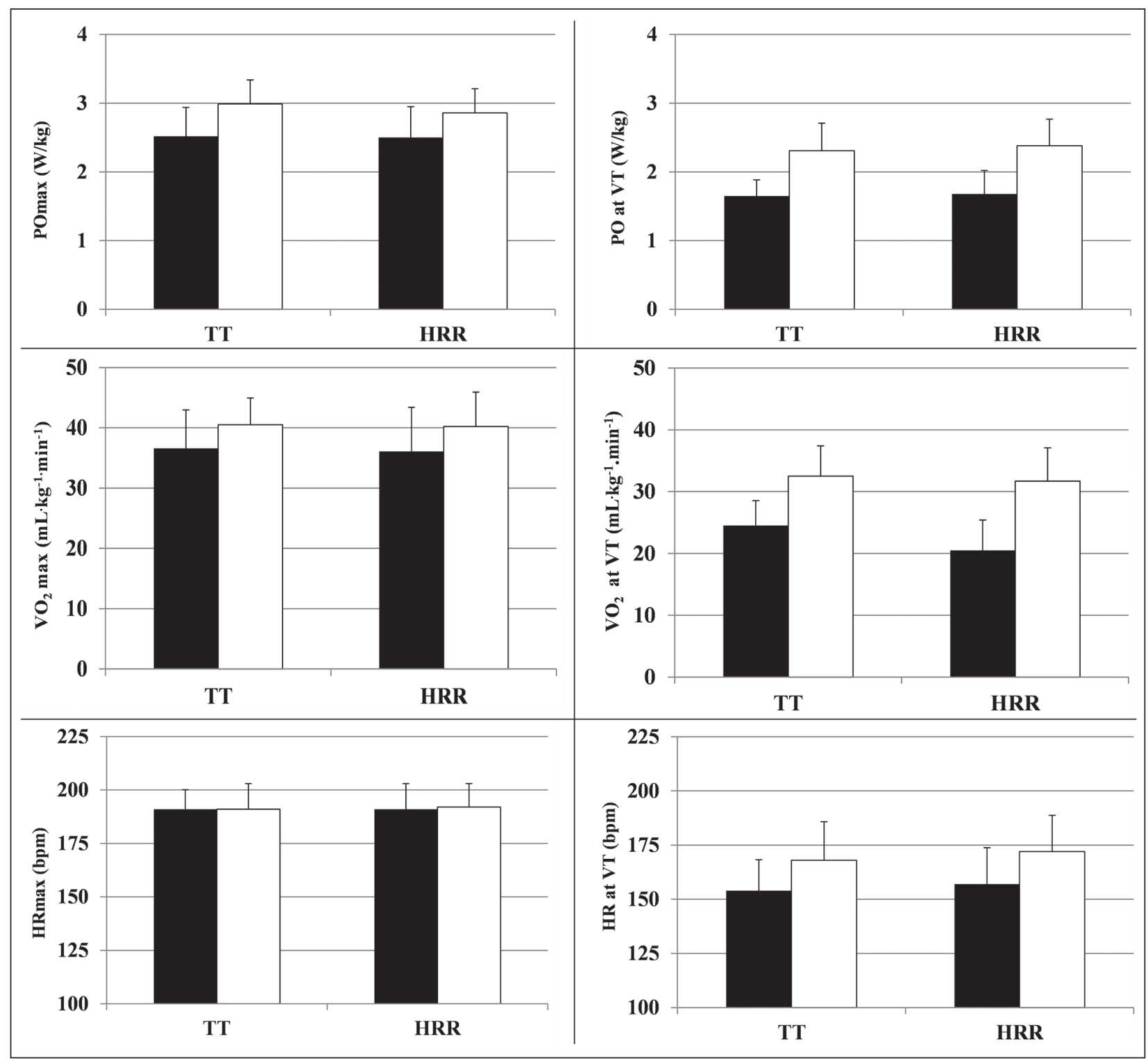

Figure 3. Changes in maximal responses and responses at the ventilatory threshold (VT) consequent to the training in the Talk Test and Heart Rate Reserve groups. The solid bars represent pretesting values and the open bars represent posttesting values. Data represent mean and standard deviation.

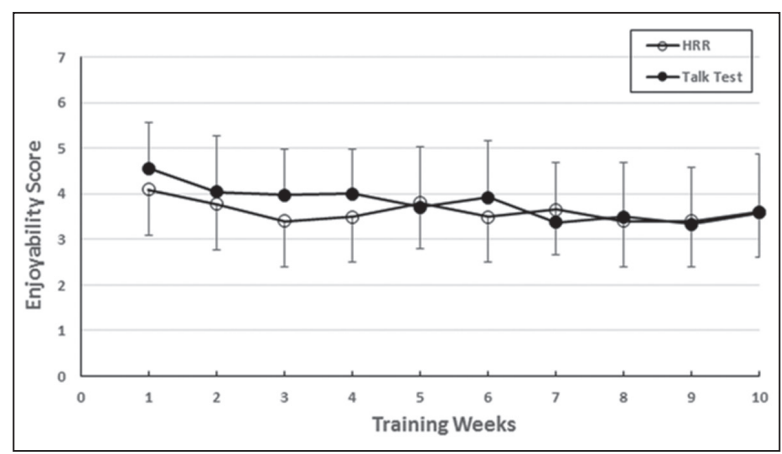

Figure 4. Changes in exercise enjoyability during exercise in the Talk Test (closed symbols) and Heart Rate Reserve (open symbols) groups across the 10 weeks of training. Data represent mean and standard deviation. the subjects were relatively young and had relatively high pre-training values of $\mathrm{VO}_{2} \max$ (Ekblom, 1968). The magnitude of improvement in the $\mathrm{VO}_{2}$ at VT $(\sim 45 \%)$ is likewise in the range of improvement often observed in similar training studies (Parfitt, et al., 2012).

Training intensity in the TT group during the first 4-8 weeks of intervention was higher than in the $\%$ HRR group. These differences were secondary to guidelines provided by ACSM (Riebe, 2017) for training sedentary individuals, where there is a stepwise increase in training intensity over time. This approach has long acceptance. However, it is limited by the absolute need to establish maximal 
HR before the training program starts. In the TT group, using an inherently simpler method of regulating training, subjects were kept just below the equivocal stage of the TT. Previous studies have suggested that when using this strategy, exercise intensity falls into normally accepted ranges of training intensity, including \%HRR (DehartBeverley, et al., 2000; Foster, et al., 2008a, 2009; Goode, et al., 1998) and RPE (Christen, Foster, Porcari, \& Mikat, 2016; Foster, et al., 2008b, 2009). These findings were reinforced in the present study, in which the training intensity in the TT group averaged $72 \%$ HRR and 13.4 on the RPE scale across the 10 weeks of training. Indeed, it can be argued that the \%HRR approach was too easy of an approach to regulating exercise training, as the RPE was only 10 during the first week. Parfit, Evans and Eston (2012) have shown that regulating intensity at $\mathrm{RPE}=13$ is both a pleasant and effective method for regulating training. The existing $\% \mathrm{HRR}$ guidelines have evolved over more than 40 years of experience, and are clearly safe and effective. However, given that they require the complication of establishing maximal HR, measuring HR during training, and are biased toward rather easy training during the first week, it can be argued that they are less effective than ideal.

The results for the TT group in the current study are similar to the findings of Parfitt, Evans, and Eston (2012), who also used subjective measures to guide exercise training. In that study, subjects completed $3 \times 30$-minute training sessions per week for 8 weeks, targeting an intensity corresponding to RPE 13. Maximal oxygen consumption improved by $17.2 \%$ and $\mathrm{VO}_{2}$ at VT increased by $28.1 \%$. The similar results are not unforeseen, since their subjects exercised between $61-64 \%$ of $\mathrm{VO}_{2} \mathrm{max}$, and subjects in the TT group exercised between $70-75 \%$ HRR and at an average RPE of 13.4.

One of the more interesting findings of the study was the decrease in the enjoyment of exercise across the study. We have previously observed a similar response, during both steady-state training and high-intensity interval training (Foster, et al., 2015). Since the intensity of exercise in the present study was decidedly moderate, it seems unlikely that the intensity of training was a primary cause for the declining enjoyment of exercise. It is tempting to speculate that the constrained nature of the exercise training program, necessary for appropriate rigor in a scientific comparison, led to a decrease in enjoyment of training. Certainly, the exercise industry is well known for frequently developing "new" training techniques, and the promotion of the "most effective" and "most scientific" is endemic within the exercise industry. Perhaps more than any physiological value of a "new" training technique, the reduction in boredom during training, attributable to novel approaches to guiding exercise, may contribute to retained enjoyment of exercise. To the degree that greater enjoyment leads to better longterm compliance with exercise training, the training variety that is absent in controlled training studies would be important to the well-established longterm health benefits of long-term exercise (Arem, et al., 2015; Ross, et al., 2016).

In summary, this study demonstrates that the response to an exercise training intervention program, in healthy, sedentary young adults is similar regardless of whether the exercise training intensity is guided conventionally, by $\% \mathrm{HRR}$, or by TT. These findings should allow simpler approaches to exercise prescription, and should augment other subjective approaches to guiding exercise training intensity (e.g., RPE) (Eston, 2012; Parfitt, et al., 2012). To our knowledge, these data are the first evidence, from a randomized trial, of the efficacy of TT as a tool for guiding exercise training intensity. From a practical standpoint, the TT method of training control results in slightly higher training intensities during the early weeks of training. However, we felt that the method had to be tested according to the background information on the method. While \%HRR was higher, RPE using this method was exactly within common recommendations for fitness training (e.g., RPE=13-14).

\section{References}

Arem, H., Moore, S., Patel, A., Hartge, P., Berrington de Gonzalez, Visvanathen, K., et al. (2015). Leisure time physical activity and mortality. Journal of American Medical Association, 176, 959-967.

Ballweg, J., Foster, C., Porcari, J.P, Haible, S., Aminaka, N., \& Mikat, R.P. (2013). Reliability of the Talk Test as a surrogate of ventilatory and respiratory compensation thresholds. Journal of Sports Science and Medicine, 12, 610-611.

Borg, G. (1998). Borg's Perceived Exertion and Pain Scales. Champaign, IL: Human Kinetics.

Brawner, C.A., Keteyian, S.J., \& Czaplicki, T.E. (1995). A method of guiding exercise intensity: The Talk Test. Medicine and Science in Sports and Exercise, 27, 241.

Brawner, C.A., Vanzant, M.A., Ehrman, J.K., Foster, C., Porcari, J.P., Kelso, A.J., \& Keteyian, S.J. (2006). Guiding exercise using the Talk Test among patients with coronary artery disease. Journal of Cardiopulmonary Rehabilitation, 26, 72-75. 
Cannon, C., Foster, C., Porcari, J.P., Skemp-Arlt, K., Fater, D.C.W., \& Backes, R. (2004). The Talk Test as a measure of exertional ischemia. American Journal of Medicine in Sport, 6, 52-57.

Christen, J., Foster, C., Porcari, J.P., \& Mikat, R.P. (2016). Temporal robustness of the session RPE. International Journal of Sports Physiology and Performance, 11, 1088-1093.

Cowan, R.E., Ginnity, K.L., Kressler, J., \& Nash, M.S. (2012). Assessment of the Talk Test and Rating of Perceived Exertion for exercise intensity prescription in persons with paraplegia. Topics in Spinal Cord Injury and Rehabilitation, 18, 212-219.

Creemers, N., Foster, C., Porcari, J.P., Cress, M.L., \& de Koning, J.J. (2017). The physiological mechanism behind the Talk Test. Kinesiology, 49(1), 3-8

Dehart-Beverly, M., Foster, C., Porcari, J.P., Fater, D.C.W., \& Mikat, R.P. (2000). Relationship between the Talk Test and ventilatory threshold. Clinical Exercise Physiology, 2, 34-38.

Ekblom, B. (1968). Effect of physical training on oxygen transport system in man. Acta Physiologica Scandinavica Supplementum, 328, 1-45.

Eston, R. (2012). Use of Ratings of Perceived Exertion in sports. International Journal of Sports Physiology and Performamce, 7, 175-182.

Foster, C., Farland, C.V., Guidotti, F., Harbin, M., Roberts, B., \& Scheutte, J. (2015). The effects of high intensity interval training vs steady state training on aerobic and anaerobic capacity. Journal of Sports Science and Medicine, 14, 747-755.

Foster, C., Florhaug, J.A., Franklin, J, Gottschall, L., Hrovatin, L.A., Parker, S., Doleshal, P., \& Dodge, C. (2001). A new approach to monitoring exercise training. Journal of Strength and Conditioning Research, 15, 109-115.

Foster, C., Porcari, J.P., Anderson, J., Paulson, M., Smaczny, D., Webber, H., \& Udermann, B. (2008a). The Talk Test as a marker of exercise training intensity. Journal of Cardiopulmonary Rehabilitation and Prevention, 28, 24-30.

Foster, C., Porcari, J.P., Battista, R.A., Udermann, B., Wright, G., \& Lucia, A. (2008b). The risk in exercise training. American Journal of Lifestyle Medicine, 2, 279-288.

Foster, C., Porcari, J.P., Gibson, M., Wright, G., Greany, J., Talati, N., \& Recalde, P. (2009). Translation of submaximal exercise test responses to exercise prescription using the Talk Test. Journal of Strength and Conditioning Research, 23, 2425-2429.

Goode, R. (2008). A personal insight into the origin of the Talk Test. Journal of the Canadian Society of Sports Medicine, 1, 5-8.

Goode, R.C., Mertens, R., Shaiman, S., \& Mertens, J. (1998). Voice, breathing, and the control of exercise intensity. Advances in Experimental Medicine and Biology, 450, 223-229.

Gormley, S.E., Swain, D.P., High, R., Spina, R.J., Dowling, E.A., Kotipalli, U.S., \& Gandrakota, R. (2008). Effect of intensity of aerobic training on $\mathrm{VO}_{2}$ max. Medicine and Science in Sports and Exercise, 7, 1336-1343.

Jeanes, E.A., Foster, C., Porcari, J.P., Gibson, M., \& Doberstein, S. (2011). Translation of exercise testing to exercise prescription using the Talk Test. Journal of Strength and Conditioning Research, 25, 590-596.

Katch, V., Weltman, A., Sady, S., \& Freedson, P. (1978). Validity of the relative percent concept for equating training intensity. European Journal of Applied Physiology, 39, 219-227.

Loose, B.D., Christiansen, A.M., Smolczyk, J.E., Roberts, K.L., Budziszewska, A., Hollatz, C.G., \& Norman, J.F. (2012). Consistency of the counting Talk Test for exercise prescription. Journal of Strength and Conditioning Research, 26, 1701-1707.

Lyon, E., Menke, M., Foster, C., Porcari, J.P., Gibson, M., \& Bubbers, T. (2014). Translation of incremental Talk Test responses to steady-state exercise training intensity. Journal of Cardiopulmonary Rehabilitation and Prevention, 34, 271-275.

Mezzani, A., Hamm, L.F., Jones, A.M., McBride, P., Moholdt, T., Stone, J., \& Williams, M.A. (2012). Aerobic exercise intensity assessment and prescription in cardiac rehabilitation: A joint position statement of the European Association for Cardiovascular Prevention and Rehabilitation, the American Association of Cardiovascular and Pulmonary Rehabilitation, and the Canadian Association of Cardiac Rehabilitation. Journal of Cardiopulmonary Rehabilitation and Prevention, 32, 327-350.

Nielsen, S., Buus, L., Hage, T., Olsen, H., Walsøe, M., \& Vinther, A. (2014). The graded cycling test combined with the Talk Test is reliable for patients with ischemic heart disease. Journal of Cardiopulmonary Rehabilitation and Prevention, 34, 276-280.

Norman, J.F., Hopkins, E., \& Crapo, E. (2008). Validity of the counting Talk Test in comparison with standard methods of estimating exercise intensity in young healthy adults. Journal of Cardiopulmonary Rehabilitation and Prevention, 28, 199-202.

Parfitt, G., Evans, H., \& Eston, R. (2012). Perceptually regulated training at RPE13 is pleasant and improves physical health. Medicine and Science in Sports and Exercise, 44, 1613-1618.

Persinger, R., Foster, C., Gibson, M., Fater, D.C., \& Porcari, J.P. (2004). Consistency of the Talk Test for exercise prescription. Medicine and Science in Sports and Exercise, 36, 1632-1636.

Petersen, A.K., Maribo, T., Hjortdal, V.E., \& Laustsen, S. (2014). Intertester reliability of the Talk Test in a cardiac rehabilitation population. Journal of Cardiopulmonary Rehabilitation and Prevention, 34, 49-53. 
Pollock, M.L. (1973). The quantification of endurance training programs. Exercise and Sport Science Reviews, 1, $155-188$.

Pollock, M.L., Foster, C., Rod, J.L., \& Wible, G. (1982). Comparison of methods for determining exercise training intensity for cardiac patients and healthy adults. Advances in Cardiology, 31, 129-133.

Quinn, T.J., \& Coons, B.A. (2011). The Talk Test and its relationship with the ventilatory and lactate thresholds. Journal of Sports Science, 29, 1175-1182.

Recalde, P.T., Foster, C., Skemp-Arlt, K., Fater, D.C.W., Neese, C.A., Dodge, C., \& Porcari, J.P. (2002). The Talk Test as a marker of ventilatory threshold. South African Journal of Sports Medicine, 9, 5-8.

Riebe, D. (2017). ACSM's Guidelines for Exercise Testing and Prescription (10 ${ }^{\text {th }}$ ed.). Wolters Kluwer.

Robergs, R., \& Landwehr, R. (2002). The surprising history of the "HRmax=220-age" equation. Journal of Exercise Physiology, 5, 1-10.

Rodriguez-Marroyo, J.A., Villa, J.G., Garcia-Lopez, J., \& Foster, C. (2013). Relationship between the Talk Test and ventilatory thresholds in well-trained cyclists. Journal of Strength and Conditioning Research, 27, $1942-1949$.

Ross, R., Blair, S.N., Arena, R., Church, T.S., Despres, J.P., Franklin, B.A., Haskell, W.L., Kaminsky, L.A., Levine, B.D., Lavie, C.J., Myers, J., Niebauer, J., Sallis, R., Sawada, S.S., Sui, X. \& Wisløff, U. (2016). Importance of assessing cardiorespiratory fitness in clinical practice: A case for fitness as a clinical vital sign: A scientific statement from the American Heart Association. Circulation, 134, 1-47.

Scharhag-Rosenberger, F., Meyer, T., Gässler, N., Faude, O., \& Kindermann, W. (2010). Exercise at given percentages of $\mathrm{VO}_{2}$ max: Heterogeneous metabolic responses between individuals. Journal of Science in Medicine and Sport, 13, 74-79.

Schroeder, M.M., Foster, C., Porcari, J.P., \& Mikat, R.P. (2017). Effects of speech passage length on accuracy of predicting metabolic thresholds using the Talk Test. Kinesiology, 49(1), 9-14.

Stanley, D.M., \& Cumming, I. (2010). Are we having fun yet? Testing the effects of imagery use on the affective and enjoyment responses to acute moderate exercise. Psychology of Sport Exercise, 11, 582-590.

Voelker, S., Foster, C., Porcari, J.P., Skemp-Arlt, K.M., Brice, G., \& Backes, R. (2001). Relationship between the Talk Test and ventilatory threshold in cardiac patients. Clinical Exercise Physiology, 4, 120-123.

Woltmann, M.L., Foster, C., Porcari, J.P., Camic, C.L., Dodge, C., Haible, S., \& Mikat, R.P. (2015). Evidence that the Talk Test can be used to regulated exercise intensity. Journal of Strength and Conditioning Research, 29, 1248-1254.

Zanettini, R., Centeleghe, P., Franzelli, C., Mori, I., Benna, S., Penati, C., \& Sorlini, N. (2013). Validity of the Talk Test for exercise prescription after myocardial revascularization. European Journal of Preventative Cardiology, 20, 376-382.

Submitted: July 19, 2017

Accepted: October 2, 2017

Published Online First: January 15, 2018

Correspondence to:

Carl Foster, Ph.D.

Department of Exercise and Sport Science

133 Mitchell Hall

University of Wisconsin-La Crosse

La Crosse, WI 54601

Phone: 608-785-8687

Fax: 608-785-8686

E-mail: cfoster@uwlax.edu

\section{Acknowledgements}

Funding for this study was provided by the American Council on Exercise.

\section{Conflict of interest}

The authors declare no conflicts of interest. 